\title{
Validation of SSR Markers Linked to Flowering Time QTLs in Sorghum through Progeny Test
}

\author{
Md. Nashir Uddin and Kazutoshi Okuno \\ Graduate School of Life and Environmental Sciences, University of Tsukuba, Tennodai 1-1-1, Tsukuba 305-8572, Japan
}

\begin{abstract}
Flowering time is critically important for crop yield, and detection of its genetic factors with strongly associated DNA markers is necessary in breeding programs. This study was undertaken to validate the quantitative trait loci (QTLs) underlying flowering time of sorghum based on the association between genotypes at SSR marker loci and flowering time in $\mathrm{F}_{3}$ family lines from self-pollinated heterozygous $\mathrm{F}_{2}$ plants developed by crossing between " $\mathrm{SC} 112$ " - an early flowering variety from Ethiopia and "Kikuchi Zairai" - a late flowering variety from Japan. The results showed that the SSR markers linked to the QTLs on sorghum chromosomes 1, 2, 3, 5b, 7 and $8 \mathrm{~b}$ were significantly $(P<0.05)$ associated with flowering time, and these markers and the QTLs reported previously are valid. On the other hand, the genotypes at the marker locus SB596 of $q F T 1-2$ on chromosome 1 was not significantly associated with flowering time. The valid DNA markers, SB258 in $q F T 1-1, \mathrm{SB} 1512$ in $q F T 2$, SB1839 in $q F T 3$, SB3369 in $q F T 5 b$, SB4096 in $q F T 7$ and SB4540 and SB4660 in qFT8b, might be useful for DNA-marker assisted breeding.
\end{abstract}

Key words: Flowering time, QTL validation, progeny test, marker assisted selection.

\section{Introduction}

Sorghum (Sorghum bicolor L. Moench) is a cultivated tropical cereal grass, and major staple crop and source of income for the people in Western and Central Africa. It is rich in antioxidants, and preferred by the gluten-intolerant consumers [1]. It is also used as forage crop for animal feedstock and biofuel production in many countries worldwide [2, 3]. The success of sorghum production is determined to a considerable extent by the appropriateness of the flowering time for the specific growing environment. The flowering time as well as its photoperiodic regulation is one of the major factors in regional climatic adaptation of elite germplasm [4]. Recent evidence also showed that flowering time genes affect hybrid vigor and thus are likely to impact on yield $[5,6]$.

Mapping of sorghum genome using DNA markers began in early 1990's and several linkage maps had been constructed [7-10]. These linkage maps are useful for identifying genes or quantitative trait loci

Corresponding author: Md. Nashir Uddin, Ph.D., research fields: plant breeding and genetics.
(QTLs) for both qualitative and quantitative traits [11]. To date, a large number of QTLs have been reported to be associated with flowering time and photoperiod sensitivity [6, 10, 12-18]. However, the contribution of detected QTLs to cultivar development has been the minimal, and only a few successful applications of marker assisted selection (MAS) for the improvement of quantitative traits have been noticed [19-22]. A primary reason for limited deployment is the unreliable markers in predicting the desired phenotypes due to the weak linkage between QTL and marker loci. Several factors contribute to the unreliability of molecular markers, including mapping of independent (unlinked) genetic markers throughout a genome that may raise false-positive results [23], mapping of QTLs using different algorithms (e.g., single marker analysis (SMA), simple interval mapping (SIM), composite interval mapping (CIM), multiple interval mapping (MIM), etc.) that may raise different results, and epistasis between the QTL and various other loci [24] that may affect the magnitude of expression of the QTL [25]. Also, environmental effects, population size, experimental error and 
genetic properties of QTLs influence the detection of QTLs in a segregating population and affect the reliability over molecular markers [26].

Marker assisted introgression of known gene is useful for breeding crops with traits of interest. To successfully conduct MAS, it is imperative to subsequently conduct validation studies for the detected QTLs and linked marker loci [27]. For molecular marker validation, Haussmann et al. [28] used multiple mapping populations and performed interval mapping for sorghum stay-green QTLs validation, and Micic et al. [29] used selective genotyping approach for rot resistant QTLs in sunflower. Current attention is now directed to fine-mapping and high-resolution mapping [30] by developing near isogenic line (NIL) for the respective QTL. Previously, Lander and Botstein [31] suggested for genotyping only the phenotype that deviates substantially from the mean of the population, called progeny test. Khoorneef et al. [32] also suggested progeny test using heterogeneous inbred lines with the same genetic background for validation of QTLs without segregation of modifiers, and concluded that progeny test is more efficient than increasing the size of the $F_{2}$ population. Previously, progeny test had been used by Holland et al. [33] to analyze QTLs for southern corn rust disease and Bulrich et al. [34] to validate the thermo-sensitive earliness per se gene in wheat.

In the preceding study, El-Mannai et al. [6] had identified nine QTLs for flowering time using $F_{2}$ population under natural day length, and the current study was conducted to validate these detected QTLs using $F_{3}$ family lines from heterozygous $F_{2}$ plants at each SSR marker loci in same growing environment through progeny test.

\section{Materials and Methods}

\subsection{Plant Materials}

$\mathrm{F}_{3}$ family lines from heterozygous $\mathrm{F}_{2}$ plants, developed by El-Mannai et al. [6] by making cross between "SC112" - an early parent from Ethiopia and "Kikuchi Zairai" - a late parent from Japan (Fig. 1) for the genotypes at each of SSR marker loci (Table 1), were used for progeny test as explained by Lander and

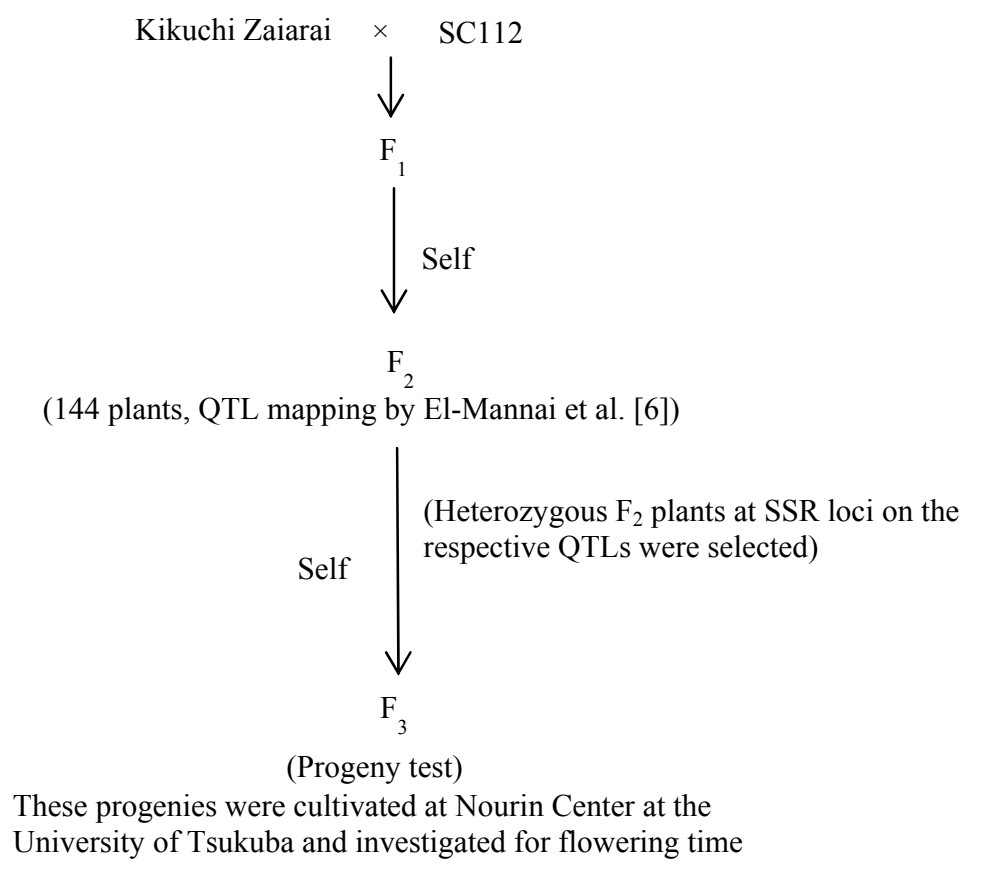

Fig. 1 Development of hybrid populations and progenies derived from a cross between Kikuchi Zairai (late flowering parent from Japan) and SC112 (early flowering parent from Ethiopia). 
Table 1 List of QTLs selected for validation study under natural day length condition reported by El-Mannai et al. [6].

\begin{tabular}{|c|c|c|c|c|c|c|c|}
\hline QTLs & Chr. & Markers interval & Map position (cM) & LOD & Additive effect* & Dominance & Var.** \\
\hline \multirow{2}{*}{$q F T 1-1$} & \multirow{2}{*}{1} & SB105 & 112.0 & \multirow{2}{*}{2.6} & \multirow{2}{*}{3.5} & \multirow{2}{*}{-5.1} & \multirow{2}{*}{5.3} \\
\hline & & SB258 & 120.3 & & & & \\
\hline \multirow{2}{*}{$q F T 1-2$} & \multirow{2}{*}{1} & SB596 & 170.3 & \multirow{2}{*}{4.2} & \multirow{2}{*}{3.7} & \multirow{2}{*}{-4.0} & \multirow{2}{*}{3.4} \\
\hline & & SB666 & 181.9 & & & & \\
\hline \multirow{2}{*}{$q F T 2$} & \multirow{2}{*}{2} & SB1406 & 60.2 & \multirow{2}{*}{6.0} & \multirow{2}{*}{5.7} & \multirow{2}{*}{9.7} & \multirow{2}{*}{9.2} \\
\hline & & SB1512 & 81.0 & & & & \\
\hline \multirow{2}{*}{$q F T 3$} & \multirow{2}{*}{3} & SB1839 & 101.7 & \multirow{2}{*}{5.6} & \multirow{2}{*}{5.1} & \multirow{2}{*}{-2.4} & \multirow{2}{*}{6.3} \\
\hline & & SB1779 & 123.1 & & & & \\
\hline \multirow{2}{*}{$q F T 5 b$} & \multirow{2}{*}{$5 b$} & SB3117 & 77.5 & \multirow{2}{*}{6.5} & \multirow{2}{*}{6.4} & \multirow{2}{*}{-7.1} & \multirow{2}{*}{6.5} \\
\hline & & SB3369 & 101.3 & & & & \\
\hline \multirow{2}{*}{$q F T 7$} & \multirow{2}{*}{7} & SB4017 & 34.7 & \multirow{2}{*}{5.0} & \multirow{2}{*}{3.6} & \multirow{2}{*}{-6.0} & \multirow{2}{*}{7.3} \\
\hline & & SB4096 & 53.0 & & & & \\
\hline aFT8 & 8 & SB4292 & 55.1 & 27 & 52 & 75 & 68 \\
\hline QFIO & $\gamma$ & SB4327 & 64.9 & 2.1 & 3.2 & -1.5 & 0.8 \\
\hline aFTRh & $8 \mathrm{~h}$ & SB4660 & 112.7 & 48 & 36 & -62 & 77 \\
\hline पF 100 & oo & SB4540 & 141.6 & 4.0 & 3.0 & -0.2 & 1.1 \\
\hline & & SB5596 & 135.3 & & & & \\
\hline$q F 110$ & 10 & SB5142 & 155.4 & 4.3 & 0.0 & -5.4 & 1.5 \\
\hline
\end{tabular}

Chr.: chromosomes; LOD: stands for logarithm of odds; *: SC112 allele decreased the number of days to flowering; **: phenotypic variation explained by each QTL.

Botstein [31]. The numbers of $F_{3}$ family line entries for each SSR marker evaluated are shown in Table 2.

Respective $\mathrm{F}_{3}$ family lines with five plants and their parental cultivars were sown in early May 2011 in the experimental field at the University of Tsukuba under natural day length condition with a planting density of $30 \mathrm{~cm} \times 20 \mathrm{~cm}$. During the growing season, day length ranged from $14.3 \mathrm{~h}$ in May, $15.0 \mathrm{~h}$ in June, July and August to $13 \mathrm{~h}$ in September. And from September, the day length decreased further to $12.5 \mathrm{~h}$. Standard agronomic practices were applied from sowing to harvest. The flowering time was scored as the number of days from sowing to the time when $50 \%$ of the panicle flowered.

\subsection{Isolation of Genomic DNA}

The leaves of 50-day-old plants were sampled and used to isolate genomic DNA. Whole genomic DNA was extracted from the leaf tissues following the method described by Murray and Thompson [35] with minor modifications. The extraction buffer was composed of $2 \% \mathrm{CTAB}, 50 \mathrm{mM}$ Tris- $\mathrm{HCl}(\mathrm{pH} 8.0)$,
$10 \mathrm{mM}$ EDTA, $0.7 \mathrm{M} \mathrm{NaCl}, 0.1 \%$ SDS, $0.1 \mathrm{mg} / \mathrm{mL}$ proteinase $\mathrm{K}, 2 \%$ insoluble PVP and $2 \%$ 2-mercaptoethanol. To remove the cellular debris and proteins, chloroform-isoamyl alcohol $(24: 1 \mathrm{v} / \mathrm{v})$ was used. The DNA was then precipitated by adding 2-propanol, and the precipitate was rinsed with $70 \%$ and then $95.5 \%$ ethanol. The final precipitate was dissolved in $50 \mu \mathrm{L}(1: 10)$ Tris-EDTA (TE) and stored at $4{ }^{\circ} \mathrm{C}$.

\subsection{Screening of SSR Markers and Polymorphism Analysis}

A total of 18 markers flanked the nine QTLs on different chromosomes reported by El-Mannai et al. [6] were primarily chosen for progeny test (Table 1). More than $60 \%$ of markers appeared to be dominant type SSR markers. Finally, eight markers closer to the QTLs on chromosomes 1, 2, 3, 5b, 7 and $8 \mathrm{~b}$ were screened for genotyping for the progeny test. Parental accessions "SC112" and "Kikuchi Zairai" were used to identify the SSR polymorphisms associated with the QTLs for flowering time. Primer sequence information is given in the Appendix Table 1. 
Table 2 Number of entries evaluated genotypes at the closest marker loci to the QTLs selected for progeny test.

\begin{tabular}{lll}
\hline QTLs & SSR markers & Total number of $\mathrm{F}_{3}$ progeny lines \\
\cline { 2 - 3 } & & SC112 $\times$ Kikuchi Zairai \\
\hline qFT1-1 & SB258 & 48 \\
$q F T 2$ & SB596 & 55 \\
$q F T 3$ & SB1512 & 51 \\
$q F T 5 b$ & SB1839 & 60 \\
$q F T 7$ & SB3369 & 51 \\
qFT8b & SB4096 & 50 \\
& SB4540 & 51 \\
\hline
\end{tabular}

SC112 = early parent; Kikuchi Zairai = late parent.

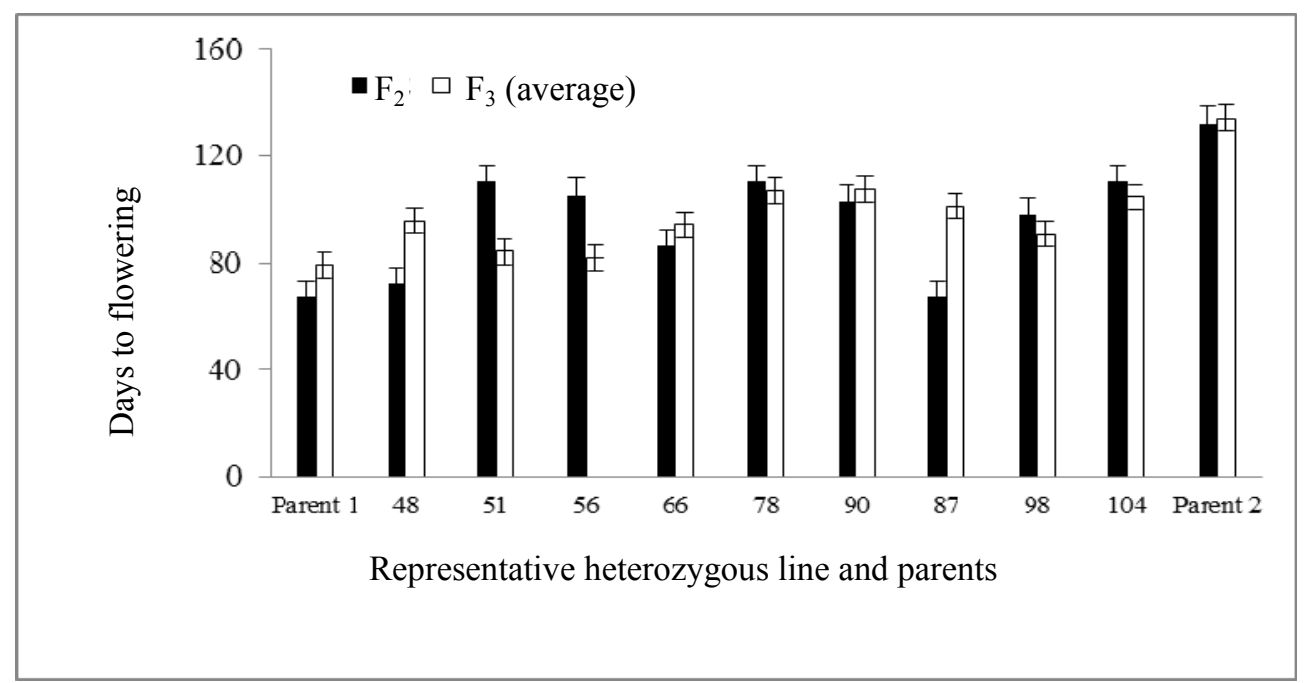

Fig. 2 Frequency distribution of representative heterozygous $F_{2}$ and $F_{3}$ lines with their parents.

Parent 1: SC112; parent 2: Kikuchi Zairai.

\subsection{PCR Conditions and Electrophoresis}

PCR amplifications were performed in a $10 \mu \mathrm{L}$ reaction mixture containing $10 \mathrm{ng}$ DNA template, $10 \times$ PCR buffer $\left(\mathrm{Mg}^{2+}\right.$ concentration: $\left.20 \mathrm{mM}\right), 2 \mathrm{mM}$ dNTP, $25 \mathrm{ng}$ each primer and $0.02 \mathrm{U}$ Blend Taq plus polymerase, using Applied Biosystems 9700 and 2700 thermal cyclers. The annealing temperature was followed as explained by El-Mannai et al. [6]. The protocol consisted of denaturation at $94^{\circ} \mathrm{C}$ for $5 \mathrm{~min}$, annealing at around $65^{\circ} \mathrm{C}$ for $30 \mathrm{~s}$ and followed by extension at $72{ }^{\circ} \mathrm{C}$ for $7 \mathrm{~min}$ and cooling at $4{ }^{\circ} \mathrm{C}$. PCR products were analyzed using high efficiency genome scanning (HEGS) [36]. The stacking gel was made from a mixture of $29 \%$ acryl amide and $1.0 \%$ $\mathrm{N}, \mathrm{N}$ '-methylene-bis-acrylamide (bis) in $0.5 \mathrm{M}$ Tris- $\mathrm{HCl}$
( $\mathrm{pH}$ 6.8), and the separation gel was made from an acrylamide mixture of $29 \%$ acrylamide and $1.0 \%$ $\mathrm{N}, \mathrm{N}$ '-methylene-bisacrylamide (bis) in 10× TBE. The electrophoresis buffer was prepared from $1 \times$ TBE. PCR products were separated at $350 \mathrm{~V}$ for $30 \mathrm{~min}$ on the stacking gel and at $200 \mathrm{~V}$ for $2.5-3 \mathrm{~h}$ on the separation gel. The gel was stained in ethidium bromide solution for 5-10 $\mathrm{min}$ and photographed using a Kodak digital science EDAS 290 ver. 3.6 with Kodak ID image analysis software ver. 3.5. Different bands generated by the same SSR primer sets were grouped according to their respective size by comparison with 100 bp ladder DNA size markers. A sample of polyacrylamide gel patterns of selected early, segregating and late $\mathrm{F}_{3}$ plants using SSR marker SB258, SB596 and SB1512 are shown in Fig. 2. 


\subsection{Progeny Test}

The basis of progeny test is to confirm the transmission of traits from $\mathrm{F}_{2}$ to $\mathrm{F}_{3}$ in association with the genotypes at SSR marker loci. If a QTL co-segregates with a marker, its presence is clarified on the basis of a significant difference in flowering time among the genotypes of SSR marker loci [31]. Association between the genotypes at SSR marker loci and flowering time were analyzed by ANOVA.

\section{Results and Discussion}

\subsection{Field Evaluation of Flowering Time}

The selected $F_{3}$ family lines grown under natural condition showed continuous variation for flowering time. The parents "SC112" and "Kikuchi Zairai" consistently displayed significant differences $(P<$ 0.001 ), and flowered at $79 \mathrm{~d}$ and $130 \mathrm{~d}$ after sowing, respectively. The distribution of the mean flowering time of in $\mathrm{F}_{3}$ family lines did not show skewness and was equally distributed between the early and late flowering phenotype (Fig. 2). This could be interpreted as an effect of complex gene actions for flowering time in sorghum.

Wide variation for flowering time was observed among the $\mathrm{F}_{3}$ plants starting from $65 \mathrm{~d}$ to $155 \mathrm{~d}$ after sowing. The flowering time of the majority of $\mathrm{F}_{3}$ plants was in between the parents, whereas few plants flowered closer to the parents.
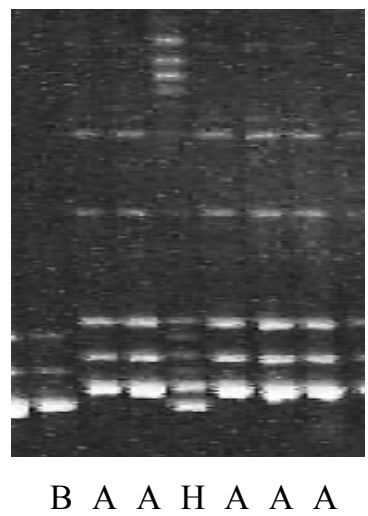

Loci I: SB258

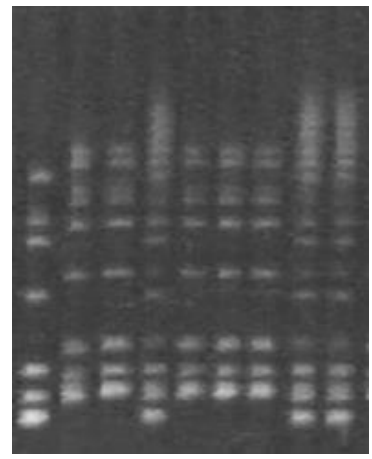

B A A H A A H H II: SB596

\subsection{Progeny Test by Phenotype-Genotype Association}

All the selected markers closer to the QTLs respectively gave amplification products and polymorphism between the parents, and samples of polymorphisms of three SSR markers are shown in Fig. 3. The genotypes at each SSR marker locus were classified into the three groups as early parental type, heterozygous and late parental types. A deviation from the expected 1:2:1 genotype frequency $(P \leq 0.05)$ was observed among the markers scored with the abundance of late parental type genotypes, except on the genotypes at marker locus SB1512, where the number of early parental type genotype was higher. Segregation of $F_{3}$ plants at each SSR marker loci are shown in Fig. 4. ANOVA analysis confirmed that QTLs for flowering time was significantly associated $(P<0.05)$ with seven marker loci of the six QTLs designated as SB258 in qFT1-1, SB1512 in $q F T 2$, SB1839 in $q F T 3$, SB3369 in $q F T 5 b$, SB4096 in $q F T 7$, SB4540 and SB4660 in qFT8b, belonging to the chromosomes 1, 2, 3, 5, 7 and 8b (Table 3, Fig. 4). The flowering time of $F_{3}$ plants with the same genotypes as the early parent varied from $65 \mathrm{~d}$ to 103 $\mathrm{d}$ after sowing. These results indicated that the linkage between QTLs and the SSR markers were transmitted over generations. The marker genotypes of SB596 in qFT1-2 did not show a significant association $(P>0.05)$ with the flowering time (Table 3, Fig. 4).

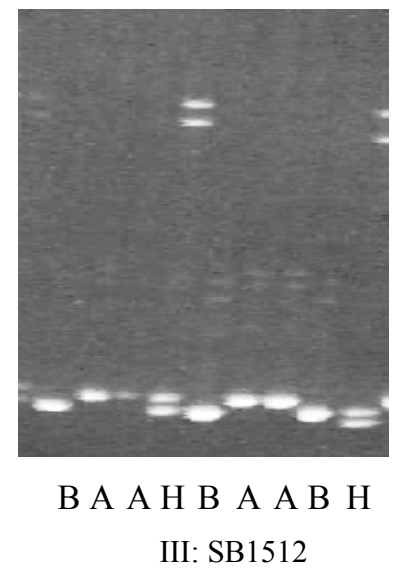

Fig. 3 Sample of polymorphism analysis using SSR marker.

B for the genotype similar to early parent (SC112), A for the genotype similar to late parent (Kikuchi Zairai) and H for heterozygous. 

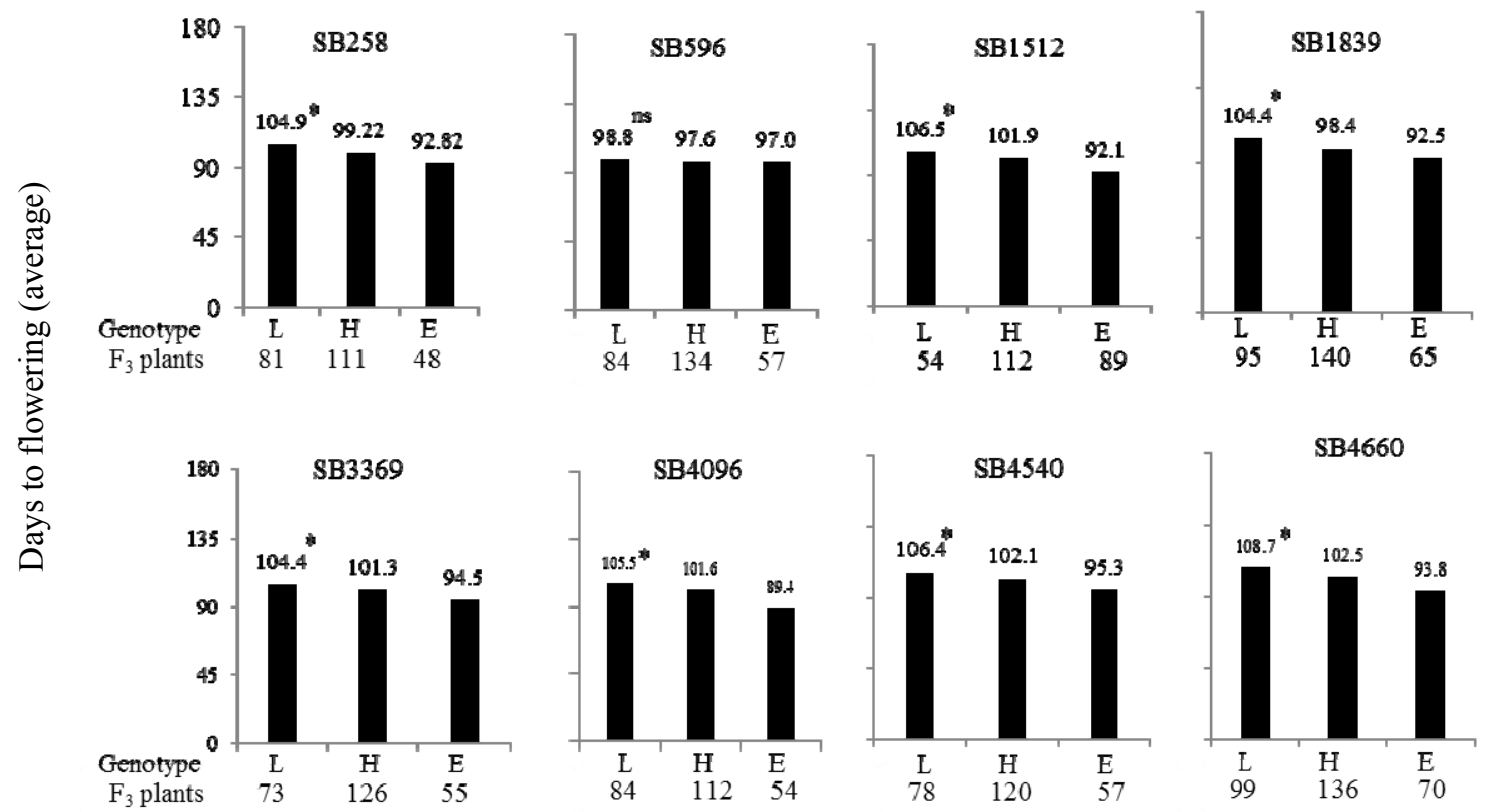

Fig. 4 Number of $F_{3}$ plants with different SSR marker genotypes at each QTL.
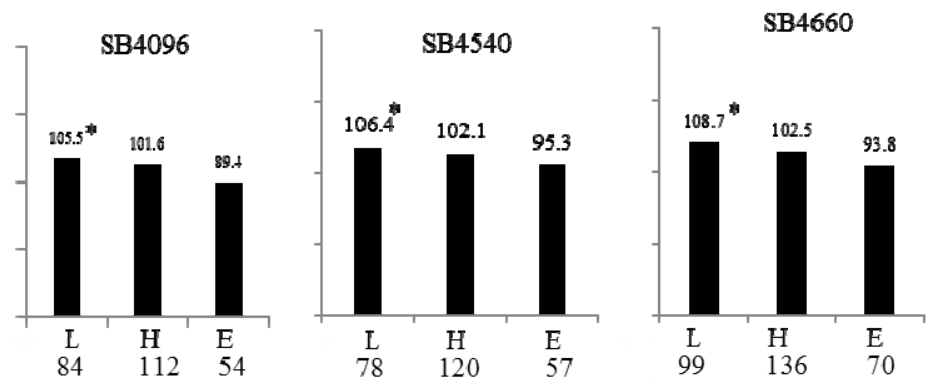

*: significant and ns: not significant at $5 \%$ level of significance.

Table 3 Flowering time of significant difference among genotypes showed by progeny test.

\begin{tabular}{|c|c|c|c|c|c|c|}
\hline \multirow{2}{*}{ QTL } & \multirow{2}{*}{ Chromosome } & \multirow{2}{*}{ Closest marker } & \multicolumn{3}{|c|}{ Mean flowering time } & \multirow{2}{*}{ Status of significance } \\
\hline & & & $\mathrm{SC} 112$ & $\mathrm{H}$ & Kikuchi Zairai & \\
\hline$q F T 1-1$ & 1 & SB258 & 92.82 & 99.22 & 104.90 & $*$ \\
\hline$q F T 1-2$ & 1 & SB596 & 97.03 & 97.59 & 98.81 & ns \\
\hline$q F T 2$ & 2 & SB1512 & 92.13 & 101.98 & 106.48 & $*$ \\
\hline qFT3 & 3 & SB1839 & 92.52 & 98.36 & 104.43 & $*$ \\
\hline$q F T 5 b$ & $5 b$ & SB3369 & 94.52 & 101.34 & 104.47 & $*$ \\
\hline$q F T 7$ & 7 & SB4096 & 89.48 & 101.69 & 105.56 & $*$ \\
\hline$q F T 8 b$ & $8 \mathrm{~b}$ & SB4540 & 95.37 & 102.16 & 106.44 & $*$ \\
\hline$q F T 8 b$ & $8 \mathrm{~b}$ & SB4660 & 93.87 & 102.56 & 108.73 & $*$ \\
\hline
\end{tabular}

*: significant at $5 \%$ level; ns: not significant at $5 \%$ level of significance.

SC112 = homozygous for early parent, $\mathrm{H}=$ heterozygous and Kikuchi Zairai = homozygous for late parent.

In this study, the progeny test was performed among the eight QTLs underlying sorghum flowering time reported by El-Mannai et al. [6], grown under natural day length condition in the $\mathrm{F}_{3}$ family lines from heterozygous $\mathrm{F}_{2}$ plants for the genotypes at each SSR marker loci, following the method explained by Lander and Botstein [31]. The QTLs from El-Mannai et al. [6] was chosen, because this was the most recent study on QTL mapping for flowering time in sorghum; its linkage map spanning length was bit long (2,464 cM), flanking markers were bit distant (average $17 \mathrm{cM}$ ), low phenotypic variance was explained by each QTL and off course easy access to receive the plant materials to conduct this study.

A great range of variation in flowering time was observed among the $F_{3}$ plants, which is similar to the results of the preceding study by El-Mannai et al. [6] and can be caused by both of the parental cultivars contributing favorable and unfavorable alleles. The marker genotype segregation analysis results showed a significant $(P \leq 0.05)$ deviation from the expected (1:2:1) genotype frequency among all the SSR marker loci with the abundance of late parental type genotypes. Paterson et al. [37] reported the deviations of restriction fragment length polymorphism (RFLP) markers using $F_{2}$ plants for QTL mapping and $F_{3}$ 
family lines for progeny test in tomato. He explained that deviation in $F_{3}$ is consistent with theoretical expectation, as heterozygosity is reduced by half in each generation. Additionally, this deviation also may be due to the use of a small number of $F_{3}$ plants (only five plants per line) in this study.

The ANOVA analysis showed that the mean flowering time of the genotypes at seven SSR markers loci were differed significantly. These markers and the closest QTLs are found as valid and transmitted over generations, even though the genetic distance between QTLs and SSR marker loci was quit long. Fuentus et al. [38] reported the linked SSR markers located at $18.5 \mathrm{cM}$ distance from the blast resistance gene $\mathrm{Pi}-1(t)$ in rice. This may be due to strong linkage between the SSR marker loci with the respective QTLs. Furthermore, the genotypes at SSR marker locus SB596 did not show significant variation in flowering time. Therefore, it was concluded that qFT1-2 is not valid over generations. This may be due to the recombination event between the marker and the QTL. This study could not use the both sides (flanked SSRs) markers in respective QTLs for progeny test due to dominant type SSRs, and genotypes of the other loci are unknown. This study recommends further studies to use these linked and new polymorphic markers by developing QTL-NILs in this population and under different genetic background and environments before gene isolation or positional cloning.

\section{Conclusions}

This study confirmed the strong linkage of flowering time QTLs and the SSR markers in the advanced generations, and these valid SSR markers, i.e., $\mathrm{SB} 258$ in $q F T 1-1, \mathrm{SB} 1512$ in $q F T 2, \mathrm{SB} 1839$ in qFT3, SB3369 in $q F T 5 b, \mathrm{SB} 4096$ in $q F T 7, \mathrm{SB} 4540$ and SB4660 in $q F T 8 b$ can be employed in MAS scheme for breeding cultivars with desirable flowering time (early or late) of sorghum.

\section{Acknowledgments}

The authors wish to thank Dr. Tariq Shehzad, assistant research scientist/assistant professor, College of Agricultural and Environmental Sciences, Plant Genome Mapping Laboratory, University of Georgia, Athens, USA, for his valuable suggestion to conduct the experiments, and also to Dr. El-Mannai Yousra for providing the SSR genotype data of $\mathrm{F}_{2}$ plants, suggestion and help in molecular laboratory.

\section{References}

[1] Harris, K., Subudhi, P. K., Borrell, A., Jordan, D., Rosenow, D., Nguyen, H., Klein, P., Klein, R., and Mullet, J. 2007. "Sorghum Stay-Green QTLs Individually Reduce Post-Flowering Drought-Induced Leaf Senescence.” J. Exp. Bot. 58 (2): 327-38.

[2] Mekbib, F. 2007. "Intra-Specific Folf Taxonomy in Sorghum (Sorghum bicolor L. Moench) in Ethiopia: Folk Nomenclature, Classification and Criteria." J. Ethnob. Ethnomed. 3: 38.

[3] Scheinost, P. L., Lammer, D. L., Cai, X., Murray, T. D., and Jones, S. 2001. "Perennial Wheat: The Development of a Sustainable Cropping System for the U.S. Pacific Northwest." A. J. Alt. Agri. 16 (4): 147-51.

[4] Jung, C., and Muller, A. E. 2009. "Flowering Time Control and Applications in Plant Breeding." Trends in Plant Sci. 14 (10): 563-73.

[5] Ni, Z., Kim, E. D., Ha, M., Lackey, E., Liu, J., Zhang, Y., Sun, Q., and Chen, Z. J. 2009. "Altered Circadian Rhythms Regulate Growth Vigor in Hybrids and Allopolyploids." Nature 457 (7227): 327-31.

[6] El-Mannai, Y., Shehzad, T., and Okuno, K. 2012. "Mapping of QTLs Underlying Flowering Time in Sorghum (Sorghum bicolor L. Moench)." Breed. Sci. 62 (2): 151-9.

[7] Pereira, M. G., Lee, M., Bramel-Cox, P., Woodman, W., Doebley, J., and Whitkus, R. 1994. "Construction of an RFLP Map in Sorghum and Comparative Mapping in Maize." Genome 37 (2): 236-43.

[8] Rami, J. F., Dufour, P., Trouche, G., Fliedel, G., Mestres, C., Davrieux, F., Blancard, P., and Hamon, P. 1998. "Quantitative Trait Loci for Grain Quality, Productivity, Morphological and Agronomic Traits in Sorghum (Sorghum bicolor L. Moench)." Theor. Appl. Genet. 97 (4): 605-16.

[9] Tuinstra, M. R., Ejeta, G., and Goldsborough, P. 1998. "Evaluation of Near-Isogenic Sorghum Lines Contrasting for QTL Markers Associated with Drought Tolerance." 
Crop Sci. 38 (3): 835-42.

[10] Feltus, F. A., Singh, H. P., Lohithaswa, H. C., Schulze, S. R., Silva, T. D., and Paterson, A. H. 2006. "A Comparative Genomics Strategy for Targeted Discovery of Single-Nucleotide Polymorphisms and Conserved-Noncoding Sequences in Orphan Crops." Plant Physiol. 140 (4): 1183-91.

[11] Mace, E. S., and Jordan, D. R. 2011. "Integrating Sorghum Whole Genome Sequence Information with a Compendium of Sorghum QTL Studies Reveals the Uneven Distribution of QTL and Gene-Rich Regions with Significant Implications for Crop Improvement." Theor. Appl. Genet. 123 (1): 169-91.

[12] Brown, P. J., Klein, P. E., Bortiri, E., Achyra, C. B., Rooney, W. L., and Kresovich, S. 2006. "Inheritance of Inflorescence Architecture in Sorghum." Theor. Appl. Genet. 113 (5): 931-42.

[13] Chantereau, J., Trouche, G., Rami, J. F., Deu, M., Barro, C., and Grivet, L. 2004. "RFLP Mapping of QTLs for Photoperiod Response in Tropical Sorghum." Euphytica 120 (2): 183-94.

[14] Crasta, O. R., Xu, W. W., Nguyen, H. T., Rosenow, D. T., and Mullet, J. 1999. "Mapping of Post Flowering Drought Resistance Traits in Grain Sorghum: Association between QTLs Influencing Premature Senescence and Maturity." Mol. Gen. Genet. 262 (3): 579-88.

[15] Hart, G. E., Schertz, K. F., Peng, Y., and Syed, N. H. 2001. "Genetic Mapping of Sorghum bicolor (L.) Moench QTLs that Control Variation in Tillering and Other Morphological Characters." Theor. Appl. Genet. 103 (8): 1232-42.

[16] Lin, Y. R., Schertz, K. F., and Paterson, A. H. 1995. "Comparative Analysis of QTLs Affecting Plant Height and Maturity across Poaceae, in Reference to an Interspecific Sorghum Population.” Genet. 141 (1): 391-411.

[17] Shiringan, A. L. 2009. "Identification of Genome Regions of Sorghum bicolor L. (Moench) Linked to Biofuel-Related Traits in Grain $\times$ Sweet Sorghum Recombinant Inbreeds Lines." Ph.D. thesis, Faculty of Agricultural Sciences, Nutritional Sciences and Environmental Management, Justus Liebig University, Giessen, Germany.

[18] Srinivas, G., Satish, K., Mohali, S. M., Reddy, R. N., Madhusudhana, R., Balakrishna, D., Venkatesh, B., Howarth, C. J., and Seetharama, N. 2008. "Development of Genic-Microsatellite Markers for Sorghum Stay Green QTL Using Comparative Genomic Approach with Rice." Theor. Appl. Genet. 117 (2): 283-96.

[19] Hu, F. Y., Tao, D. Y., Sacks, E., Fu, B. Y., Xu, P., Li, J., Yang, Y., McNally, K., Khush, K. S., Paterson, A. H., and Li, Z. K. 2003. "Convergent Evolution of
Perenniallity in Rice and Sorghum." Proc. Nat. Acad. Sci. USA 100 (7): 4050-4.

[20] Ragot, M., Gay, G., Muller, J. P., and Durovray, J. 2000. Efficient Selection for the Adaptation to the Environment through QTL Mapping and Manipulation in Maize. Mexico, DF: CIMMYT, 128-30.

[21] Ribaut, J. M., and Ragot, M. 2007. "Marker-Assisted Selection to Improve Drought Adaptation in Maize: The Backcross Approach, Perspectives, Limitations and Alternatives.” J. Exp. Bot. 58 (2): 351-60.

[22] Collard, B. C., and Mackill, D. J. 2008. "Marker-Assisted Selection: An Approach for Precision Plant Breeding in the Twenty-First Century." Phil. Trans. R. Soc. Lond. B Biol. Sci. 363 (1491): 557-72.

[23] Paterson, A. H., Bowers, J. E., Bruggmann, R., Dubchak, I., Grimwood, J., Gundlach, H., Haberer, G., Hellsten, U., Mitros, T., Poliakov, A., Schmutz, J., Spannagl, M., Tang, H., Wang, X., Wicker, T., Bharti, A. K., Chapman, J., Feltus, F. A., Gowik, U., Grigoriev, I. V., Lyons, E., Maher, C. A., Martis, M., Narechania, A., Otillar, R. P., Penning, B. W., Salamov, A. A., Wang, Y., Zhang, L., Carpita, N. C., Freeling, M., Gingle, A. R., Hash, C. T., Keller, B., Klein, P., Kresovich, S., McCann, M. C., Ming, R., Peterson, D. G., Mehboob-ur-Rahman, Ware, D., Westhoff, P., Mayer, K. F., Messing, J., and Rokhsar, D. S. 2009. "The Sorghum Bicolor Genome and the Diversification of Grasses." Nature 457 (7229): 551-6.

[24] Dudley, J. W. 1993. "Molecular Markers in Plant Improvement: Manipulation of Genes Affecting Quantitative Traits." Crop Sci. 33 (4): 660-8.

[25] Knoll, J., Gunaratna, N., and Ejeta, G. 2008. "QTL Analysis of Early Season Cold Tolerance in Sorghum." Theor. Appl. Genet. 116 (4): 577-87.

[26] Ausin, I., Alonso-Blanco, C., and Martinez-Zapater, J. M. 2005. "Environmental Regulation of Flowering." Int. J. Dev. Biol. 49 (5-6): 689-705.

[27] Langridge, P., Lagudah, E., Holton, T., Appels, R., Sharp, P., and Chalmers, K. 2001. "Trends in Genetic and Genome Analyses in Wheat: A Review." Aus. J. Agri. Res. 52 (12): 1043-77.

[28] Haussmann, B. I., Mahalkshmi, V., Reddy, B. V., Seetharama, N., Hash, C. T., and Geiger, H. H. 2002. "QTL Mapping of Stay-Green in Two Sorghum Recombinant Inbred Populations." Theor. Appl. Genet. 106 (1): 133-42.

[29] Micic, Z., Hahn, V., Bauer, E., Melchinger, A. E., Knapp, S. J., Tang, S., and Schon, C. C. 2005. "Identification and Validation of QTL for Sclerotinia midstalk Rot Resistance in Sunflower by Selective Genotyping." Theor. Appl. Genet. 111 (2): 233-42.

[30] Darvasi, A., Weireb, A., Minekij, V., Wellear, J. I., and 
Soller, M. 1993. "Detecting Marker-QTL Linkage and Estimating QTL Gene Effect and Map Location Using a Saturated Genetic Map.” Genetics 134 (3): 943-51.

[31] Lander, E. S., and Botstein, D. 1989. "Mapping Mendelian Factors Underlying Quantitative Traits Using RFLP Linkage Maps.” Genetics 121: 185-99.

[32] Koornneef, M., Alonso-Blanco, C., Peeters, A., and Stoppe, W. 2006. "Genetic Analysis, QTL Analysis." In Arabidopsis Protocols, edited by Salinas, J., and Sanchez-Serrano, J. J. Totowa, NJ: Humana Press, 65-79.

[33] Holland, J. B., Uhr, D. V., Jevers, D., and Goodman, M. M. 1998. "Inheritance of Resistance to Southern Corn Rust in Tropical-by-Cornbelt Maize Populations." Theor. Appl. Genet. 96 (2): 232-41.

[34] Bullrich, L., Appendino, M. L., Tranquilli, G., Lewis, S., and Dubcovsky, J. 2002. "Mapping of Thermo-Sensitive Earliness per se Gene on Triticum monococcum Chromosome 1A $\mathrm{A}^{\mathrm{m}}$." Theor. Appl. Genet. 105: 585-93.
[35] Murray, M. G., and Thompson, W. F. 1980. "Rapid Isolation of High Molecular Weight Plant DNA." Nuc. Acids Res. 8 (19): 4321-5.

[36] Shimizu, A., and Kawasaki, S. 2009. "Rapid Construction of a High-Density Rice Linkage Map by High Efficiency Genome Scanning (HEGS) System." Rice Sci. 16 (4): 247-53.

[37] Paterson, A. H., Damon, S., Hewitt, J. D., Zamir, D., Rabinowitch, H. D., Lincoln, S. E., Lander, E. S., and Tanksley, S. D. 1991. "Mendelian Factors Underlying Quantitative Traits in Tomato: Comparison across Species, Generations and Environments." Genetics 127 (1): 181-97.

[38] Fuentes, J. L., Correa-Victoria, F. J., Escobar, F., Prado, G., Aricapa, G., Duque, M. C., and Tohme, J. 2008. "Identification of Microsatellite Markers Linked to the Blast Resistance Gene Pi-1(t) in Rice.” Euphytica 160 (3): 295-304. 
Appendix

Table 1 Primer sequence information of the SSR markers close to the valid QTLs.

\begin{tabular}{|c|c|c|c|c|c|}
\hline \multirow{2}{*}{$\begin{array}{l}\text { Marker } \\
\text { name }\end{array}$} & \multirow[b]{2}{*}{ Repeat motif } & \multicolumn{2}{|c|}{ Sequence of primers } & \multirow{2}{*}{$\begin{array}{l}\text { Annealing } \\
\text { temperature } \\
\left({ }^{\circ} \mathrm{C}\right)\end{array}$} & \multirow{2}{*}{$\begin{array}{l}\text { Expected } \\
\text { size (bp) }\end{array}$} \\
\hline & & Forward ( $\left.5^{\prime}-3^{\prime}\right)$ & Reverse (5'-3') & & \\
\hline SB258 & (TC)4(TA)3(AT)3(AG)30(AG)3(CGC)6(TCC)3(CTC)4(AAC)3 & TGCATGAGAACCAAAGCTGGTTTA & CAGCAGTAGAGCACAGGACGTTGT & 65 & 194 \\
\hline SB1512 & (GC)3(TC)17(TC)3(CCG)3(CGC)4 & GGAGGGTACCTGGTCGTAGGTCTT & GATGCGCCCGTAGATGTCATTATT & 65 & 293 \\
\hline SB1839 & $(\mathrm{AT}) 3(\mathrm{CT}) 3(\mathrm{AG}) 31$ & TGAAGAAGCTGTCCGTTTGACAAG & AAAAAGCTGCTCCTTTGAGGCTTT & 64 & 198 \\
\hline SB3369 & (AG)6(AG)8(TTC)3(GTC)3(CTT)3(CGA)3(ACC)3 & GACAGCTGAGATCGCACTTCTCTG & CACCAGACGGGCTCTAAAAACAGT & 64 & 235 \\
\hline SB4096 & (CA)3(TC)3(AC)4(AG)16(AG)3(AG)3 & СССССТСТСАGATTCTСАСССТАТ & CCGCTTTCTCCTTAGTGACACCAT & 64 & 219 \\
\hline SB4540 & (TA)4(GAA) 19 & GAACCTTTGGGCCTAAATTGGAAG & GTATTTGTCCCCGTATTGATGCGT & 65 & 246 \\
\hline SB4660 & $\begin{array}{l}(\mathrm{GC}) 3(\mathrm{CA}) 3(\mathrm{CCG}) 3(\mathrm{CGG}) 3(\mathrm{GCT}) 8(\mathrm{GAT}) 3(\mathrm{CGA}) 3(\mathrm{CGC}) \\
5(\mathrm{GAT}) 3\end{array}$ & AACCACAACCACGGGATATCGTC & ACGAAGAACGGATGCTCGTACTG & 64 & 298 \\
\hline
\end{tabular}

The resource according to El-Mannai et al. [6]. 